\title{
Pre-Procedural Glucose Levels and the Risk for Contrast-Induced Acute Kidney Injury in Patients Undergoing Emergency Coronary Intervention
}

Hiroyuki Naruse, MD; Junnichi Ishii, MD; Tousei Hashimoto, MD; Tomoko Kawai, MD; Kousuke Hattori, MD; Masanori Okumura, MD; Sadako Motoyama, MD; Shigeru Matsui, MD; Ikuko Tanaka, MD; Hideo Izawa, MD; Masanori Nomura, MD; Yukio Ozaki, MD

Background: The incidence, risk factors, and outcome of contrast-induced acute kidney injury (Cl-AKI) in 730 patients with acute coronary syndrome (ACS) undergoing emergency percutaneous coronary intervention (PCI), whose contrast volume was below maximum allowable contrast dose (MACD) was prospectively investigated.

Methods and Results: MACD was defined as ( $5 \mathrm{ml} \times$ body weight $[\mathrm{kg}] / \mathrm{baseline}$ creatinine $[\mathrm{mg} / \mathrm{dl}])$. Cl-AKI was defined as a greater than $25 \%$ increase in creatinine from the baseline or an absolute increase of $\geq 0.5 \mathrm{mg} / \mathrm{dl}$ within $48 \mathrm{~h}$ after the procedure. Cl-AKI occurred in 212 (29\%) patients. Patients with Cl-AKI had a higher risk for in-hospital mortality $(9.4 \%$ vs. $1.5 \%, \mathrm{P}<0.001)$ and a longer stay in the coronary care unit (median, 4.0 vs. 3.0 days, $\mathrm{P}<0.001)$ compared with those without $\mathrm{Cl}-\mathrm{AKI}$. In a multivariate logistic analysis including 20 clinical variables, elevated glucose levels as variables categorized into quartiles were independently $(P<0.001)$ associated with the development of $\mathrm{Cl}-\mathrm{AKI}$. In addition, this relationship was seen in both the subgroup of patients with known diabetes and that of those without known diabetes.

Conclusions: $\mathrm{Cl}-\mathrm{AKI}$ might occur commonly and could be be associated with a more complicated clinical course in ACS patients undergoing emergency $\mathrm{PCl}$ whose contrast volume does not exceed MACD. Elevated pre-procedural glucose might be a powerful and independent risk factor for the development of $\mathrm{Cl}-\mathrm{AKI}$ in this population. (Circ J 2012; 76: 1848-1855)

Key Words: Acute coronary syndrome; Contrast-induced acute kidney injury; Glucose; Maximum allowable contrast dose; Percutaneous coronary intervention

$\mathbf{C}$ ontrast-induced acute kidney injury (CI-AKI) results from acute tubular necrosis from nephrotoxic iodinated contrast agent administered intra-arterially during a procedure as well as from other homeostatic factors. ${ }^{1-3}$ Contrast volume is a key risk factor for CI-AKI and is most crucial in high-risk patients. ${ }^{3-6}$

Previous studies have demonstrated that the risk of CI-AKI is markedly increased if contrast volume exceeds the weightand creatinine level-adjusted maximum allowable contrast dose (MACD) threshold. ${ }^{3,7-9} \mathrm{~A}$ recent large prospective clinical trial $(n=10,065)$ has shown that exceeding MACD in a patient undergoing percutaneous coronary intervention (PCI) is associated with an increased risk of CI-AKI by $45 \%$ for each $50 \%$ in excess of MACD, whereas contrast volumes below the threshold hold to a lower plateau risk of CI-AKI. ${ }^{3}$ However,
CI-AKI remains an adverse outcome for patients even when contrast volume does not exceed MACD. Furthermore, MACD is not exceeded in approximately $80 \%$ of the patients undergoing PCI. ${ }^{3}$ Thus, it is important to design studies focusing on CI-AKI in patients when contrast volume does not exceed MACD.

Elevated blood glucose levels occur commonly in patients with acute myocardial infarction (AMI), and are strongly associated with increased mortality and in-hospital complications. ${ }^{10-16}$ Some recent clinical studies have suggested that the pre-procedural glucose level might be a potential and independent risk factor for the development of CI-AKI in patients undergoing coronary angiography for $\mathrm{AMI}^{17}$ and in patients undergoing primary PCI for ST-segment elevation myocardial infarction. ${ }^{18}$ However, the relationship between the pre-

Received October 31, 2011; revised manuscript received March 22, 2012; accepted March 23, 2012; released online April 26,2012 Time for primary review: 21 days

Department of Cardiology (H.N., T.H., T.K., K.H., M.O., S. Motoyama, S. Matsui, Y.O.), Department of Joint Research Laboratory of Clinical Medicine (J.I., I.T.), Fujita Health University Hospital, Toyoake; and Department of Cardiology, Fujita Health University Banbuntane Houtokukai Hospital, Nagoya (H.I., M.N.), Japan

Mailing address: Junnichi Ishii, MD, Department of Joint Research Laboratory of Clinical Medicine, Fujita Health University School of Medicine, 1-98 Kutsukake-cho, Dengakugakubo, Toyoake 470-1192, Japan. E-mail: jishii@ fujita-hu.ac.jp

ISSN-1346-9843 doi:10.1253/circj.CJ-11-1248

All rights are reserved to the Japanese Circulation Society. For permissions, please e-mail: cj@j-circ.or.jp 


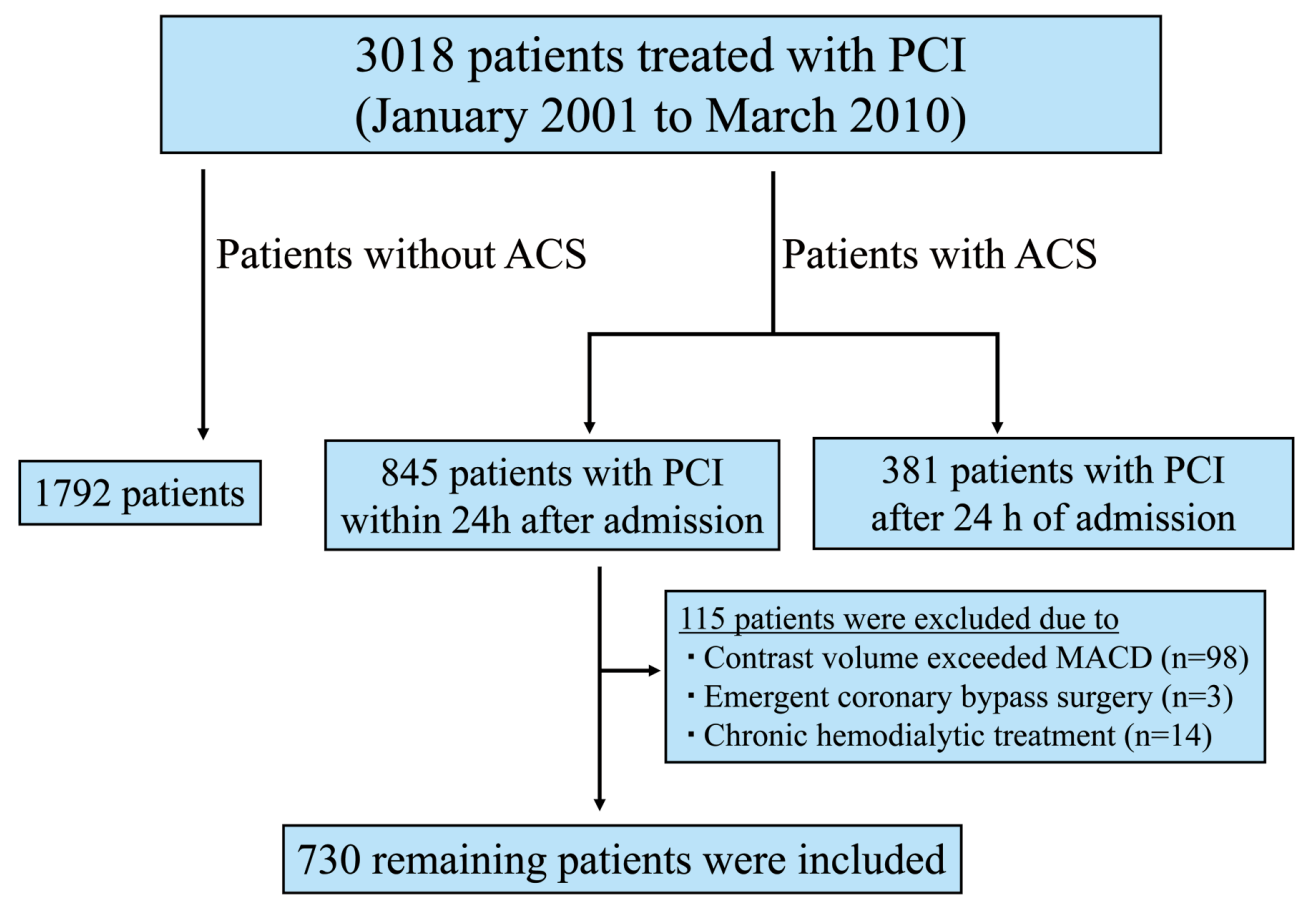

Figure 1. Diagram of patient flow and selection process for study inclusion. PCI, percutaneous coronary intervention; ACS, acute coronary syndrome; MACD, maximum allowable contrast dose.

procedural glucose level and the risk of CI-AKI has not yet been well examined in patients with acute coronary syndrome (ACS), especially in those with diabetes.

In the present study, we prospectively investigated the incidence, risk factors, and outcome of CI-AKI after emergency PCI for ACS with use of contrast volume below MACD.

\section{Methods}

\section{Study Design}

From January 2001 to March 2010, 730 consecutive patients with acute ST-segment elevation myocardial infarction or unstable angina/non-ST-segment elevation myocardial infarction undergoing emergency PCI with use of contrast volume below the MACD threshold were enrolled in the present study.

The patients were eligible for inclusion if they had been admitted within $24 \mathrm{~h}$ of the onset of chest pain that had lasted for $\geq 30$ min with ST-segment elevation of $>0.2 \mathrm{mV}$ in $\geq 2$ contiguous leads and elevation of cardiac troponin I level greater than the upper limit of normal. Patients were also enrolled if they had an episode of ischemic chest pain of $\geq 10 \mathrm{~min}$ with transient or persistent ST-segment depression $(>0.5 \mathrm{~mm}), \mathrm{T}$ wave inversion $(>1 \mathrm{~mm})$, and/or elevation of cardiac troponin I level greater than the upper limit of normal, thus presenting with refractory angina or hemodynamic instability despite optimal drug therapy within $24 \mathrm{~h}$ of admission.

MACD for each patient was calculated by using the formula proposed by Cigarroa and colleagues: ${ }^{7}$ MACD $(\mathrm{ml})=$ $(5 \times$ body weight $[\mathrm{kg}])$ divided by serum creatinine level $(\mathrm{mg} / \mathrm{dl})$ on admission. Patients were excluded if the contrast volume exceeded MACD for the interventional procedure. Patients were excluded if emergency coronary bypass surgery was required and if they had received chronic peritoneal or hemo- dialytic treatment on admission. Informed consent was obtained from all patients before participation in the study and the study protocol was approved by the Human Investigation Committee of our institution.

Calculation of the Global Registry of Acute Coronary Events (GRACE) Risk Score was based on admission data and performed as previously described. Briefly, this score consists of 8 variables; 5 semi-quantitative (age, systolic blood pressure, heart rate, creatinine, and Killip class) and 3 dichotomous variables (positive necrosis markers, ST-segment deviation, and cardiac arrest at admission). ${ }^{19}$

During hospitalization, the following adverse clinical events were considered: major bleeding requiring blood transfusion of $\geq 1$ unit, acute pulmonary edema, acute renal failure requiring emergency renal replacement therapy (hemofiltration or hemodialysis), cardiogenic shock, tachyarrhythmias or bradyarrhythmias, and cardiac death.

\section{PCI Procedure}

Emergency PCI was performed by a $24-\mathrm{h}$ on-call interventional team according to standard clinical practice by using standard guide catheters, guide wires, and balloon catheters via the femoral or radial approaches. MACD was calculated in all patients as part of the interventional team's "time out" before initiating the procedure for minimizing contrast exposure. The type of angioplasty technique and supportive pharmacologic therapies were left to the discretion of the interventional cardiologist. All patients received non-ionic, lowosmolar contrast agents. Patients received a bolus of 5,000 U heparin in the coronary care unit, followed by a bolus of $5,000 \mathrm{U}$ heparin before the procedure. After contrast exposure, patients received isotonic $(0.9 \%)$ saline intravenously at a rate of $1 \mathrm{ml} \cdot \mathrm{kg}^{-1} \cdot \mathrm{h}^{-1}$ for $12 \mathrm{~h}$. Patients with severe reductions in the 
Table 1. Baseline Clinical and Angiographic Characteristics in Patients With and Those Without Cl-AKI

\begin{tabular}{|c|c|c|c|c|}
\hline & All $(n=730)$ & $\begin{array}{l}\text { With Cl-AKI } \\
(n=212)\end{array}$ & $\begin{array}{l}\text { Without Cl-AKI } \\
(n=518)\end{array}$ & $P$ value \\
\hline Age (years) & $64(58-71)$ & $67(60-72)$ & $63(57-70)$ & 0.002 \\
\hline Male & $584(80)$ & $170(80)$ & $414(80)$ & 0.89 \\
\hline \multicolumn{5}{|l|}{ Coronary risk factor } \\
\hline Diabetes mellitus & $197(27)$ & $83(39)$ & $114(22)$ & $<0.001$ \\
\hline Hypertensin & $355(49)$ & $106(50)$ & $249(48)$ & 0.64 \\
\hline Hyperlipidemia & 237 (32) & $66(31)$ & $171(33)$ & 0.54 \\
\hline Current smoker & $318(44)$ & $90(42)$ & $228(44)$ & 0.47 \\
\hline \multicolumn{5}{|l|}{ Diagnosis } \\
\hline ST-segment elevation MI & $496(68)$ & $159(75)$ & $337(65)$ & 0.01 \\
\hline Previous MI & $85(12)$ & $23(11)$ & $62(12)$ & 0.92 \\
\hline Killip class 4 on admission & $25(3.4)$ & $12(5.7)$ & $13(2.5)$ & 0.03 \\
\hline Time to onset (h) & $6.0(3.0-10.0)$ & $6.0(3.5-9.3)$ & $6.0(3.0-12)$ & 0.76 \\
\hline SBP $(\mathrm{mmHg})$ & $134(119-151)$ & $136(120-153)$ & $133(119-150)$ & 0.57 \\
\hline DBP (mmHg) & $72(62-84)$ & $73(62-82)$ & $72(63-84)$ & 0.84 \\
\hline LVEF (\%) & $51(45-58)$ & $50(43-57)$ & $52(47-59)$ & $<0.001$ \\
\hline \multicolumn{5}{|l|}{ Laboratory parameters } \\
\hline Hemoglobin (mg/dl) & $13.8(12.6-14.9)$ & $13.7(12.4-15.0)$ & $13.9(12.6-14.9)$ & 0.37 \\
\hline Estimated GFR $\left(\mathrm{ml} \cdot \mathrm{min}^{-1} \cdot 1.73 \mathrm{~m}^{-2}\right)$ & $87.7(70.6-112)$ & $90.5(64.5-116)$ & $86.7(64.5-108)$ & 0.56 \\
\hline Estimated GFR $\left(<60 \mathrm{ml} \cdot \mathrm{min}^{-1} \cdot 1.73 \mathrm{~m}^{-2}\right)$ & $99(14)$ & $42(20)$ & $57(11)$ & $<0.001$ \\
\hline Glucose (mg/dl) & $152(120-207)$ & $198(155-261)$ & $138(115-179)$ & $<0.001$ \\
\hline Total cholesterol (mg/dl) & $194(171-216)$ & $190(163-224)$ & $194(175-216)$ & 0.35 \\
\hline Triglyceride (mg/dl) & $84(50-144)$ & $85(49-150)$ & $84(51-142)$ & 0.81 \\
\hline Low density lipoprotein (mg/dl) & $130(106-150)$ & $125(104-152)$ & $130(106-149)$ & 0.67 \\
\hline High density lipoprotein (mg/dl) & $46(39-55)$ & $43(36-53)$ & $46(39-56)$ & 0.10 \\
\hline \multicolumn{5}{|l|}{ Treatment before admission } \\
\hline ACEI and/or ARB & $255(35)$ & $72(34)$ & $181(35)$ & 0.85 \\
\hline$\beta$-blockers & $73(10)$ & $15(7)$ & $58(11)$ & 0.08 \\
\hline Calcium channel blocker & $204(28)$ & $55(26)$ & $149(29)$ & 0.50 \\
\hline Statins & $177(24)$ & $49(23)$ & $128(25)$ & 0.67 \\
\hline Oral anti-hyperglycemic agent & $143(20)$ & $76(36)$ & $67(13)$ & $<0.001$ \\
\hline Sulfonylurea & $95(13)$ & $44(21)$ & $51(10)$ & $<0.001$ \\
\hline a-Glucosidase inhibitor & $57(8)$ & $27(13)$ & $30(6)$ & 0.002 \\
\hline Thiazolidinediones & $53(7)$ & $25(12)$ & $28(5)$ & 0.003 \\
\hline Metformin & $55(8)$ & $21(10)$ & $34(7)$ & 0.16 \\
\hline Any insulin & $25(3.4)$ & $9(4.2)$ & $16(3.1)$ & 0.58 \\
\hline Atrial natriuretic peptide infusion & $53(7)$ & $17(8)$ & $36(7)$ & 0.78 \\
\hline \multicolumn{5}{|l|}{ Angiographic procedure } \\
\hline \multicolumn{5}{|l|}{ Culprit lesion } \\
\hline $\begin{array}{l}\text { Left anterior descending coronary } \\
\text { artery }\end{array}$ & $342(47)$ & $102(48)$ & $240(46)$ & 0.65 \\
\hline Left circumflex coronary artery & $118(16)$ & $36(17)$ & $82(16)$ & 0.84 \\
\hline Right coronary artery & $263(36)$ & $72(34)$ & $191(37)$ & 0.48 \\
\hline Saphenous vein bypass graft & $7(1)$ & $2(1)$ & $5(1)$ & 0.73 \\
\hline Multivessel disease & $330(45)$ & $114(54)$ & $216(42)$ & 0.003 \\
\hline Duration of procedure (min) & $54(36-77)$ & $53(34-74)$ & $55(38-80)$ & 0.52 \\
\hline Contrast volume (ml) & $220(180-270)$ & $225(180-270)$ & $218(180-270)$ & 0.85 \\
\hline Contrast ratio & $0.5(0.4-0.7)$ & $0.5(0.4-0.6)$ & $0.5(0.4-0.7)$ & 0.38 \\
\hline Stent implantation & $584(80)$ & $167(79)$ & $417(81)$ & 0.44 \\
\hline Procedural success & $708(97)$ & $206(97)$ & $502(97)$ & 0.38 \\
\hline Intra-aortic balloon pumping support & $108(15)$ & $39(18)$ & $69(13)$ & 0.10 \\
\hline
\end{tabular}

Data are expressed as median (interquartile range) or number of patients (percentage).

$\mathrm{Cl}-\mathrm{AKI}$, contrast-induced acute kidney injury; MI, myocardial infarction; SBP, systolic blood pressure; DBP, diastolic blood pressure; LVEF, left ventricular ejection fraction; GFR, glomerular filtration rate; ACEl, angiotensin converting enzyme inhibitors; ARB, angiotensin receptor blockers. 


\begin{tabular}{lcccc}
\hline Table 2. In-Hospital Clinical Complications & & & \\
& With Cl-AKI & Without CI-AKI & P value \\
CPR, VT, or VF & $18.4 \%$ & $5.8 \%$ & $<0.001$ \\
High rate atrial fibrillation & $5.7 \%$ & $0.6 \%$ & $<0.001$ \\
Acute pulmonary edema requiring mechanical ventilation & $16.0 \%$ & $3.5 \%$ & $<0.001$ \\
High degree conduction disturbances requiring pacemaker & $2.4 \%$ & $1.9 \%$ & 0.71 \\
Major bleeding requiring blood transfusion & $6.1 \%$ & $0.6 \%$ & $<0.001$ \\
Concomitant medications & & & $<0.001$ \\
Acute renal failure requiring renal replacement therapy & $3.8 \%$ & $0 \%$ & $<0.001$ \\
Patients with 2 or more clinical complications & $16.0 \%$ & $3.7 \%$ & $<0.001$ \\
In-hospital mortality & $9.4 \%$ & $1.5 \%$ & \\
\hline
\end{tabular}

$\mathrm{Cl}-\mathrm{AKI}$, contrast-induced acute kidney injury; CPR, cardiopulmonary resuscitation; VT, ventricular tachycardia; VF, ventricular fibrillation.

left ventricular ejection fraction received $0.45 \%$ saline.

Post-stenting antithrombotic treatment consisted of aspirin and either clopidogrel or ticlopidine at standard dosages.

\section{Date Collection}

Venous blood samples were obtained before initiating the procedure. At the same time, 2-dimensional echocardiography was performed by experts blinded to the study, and the left ventricular ejection fraction was calculated using a modified Simpson's method. The serum creatinine concentration was determined routinely with an enzyme method using Liquitech ${ }^{\circledR}$ Creatinine PAP II (Roche Diagnostics, Tokyo, Japan) on admission, before the procedure, and every day until at discharge from the coronary care unit. The estimated glomerular filtration rate (GFR) was calculated by the Modification of Diet in Renal Disease Study (MDRD) equation, which is recommended by the Japan Chronic Kidney Disease Initiative. ${ }^{20}$ Patients were classified as having recognized diabetes if their medical records contained documentation of previous history of diabetes, diagnosis of diabetes on admission, or use of an oral antihyperglycemic agent or insulin at the time of hospital admission.

CI-AKI was defined as $>25 \%$ increase in serum creatinine concentration from the baseline or an absolute increase of $\geq 0.5 \mathrm{mg} / \mathrm{dl}$ within $48 \mathrm{~h}$ after emergency PCI.

\section{Statistical Analysis}

All data analyses were performed with SPSS version 11.0 (SPSS Inc, Chicago, IL, USA). Differences in proportions were compared by chi-squared analysis. If not stated otherwise, continuous data are given as median $\left(25^{\text {th }}-75^{\text {th }}\right.$ percentile $)$. Differences between continuous data were tested using the MannWhitney U-test.

Univariate and multivariate logistic analyses were used to assess the predictors of CI-AKI and the predictive value of glucose levels as variables categorized into quartiles. The adjusted variables were age, male gender, medical history of hypertension, hyperlipidemia or diabetes, current smoking status, previous history of myocardial infarction, ST-segment elevation myocardial infarction, Killip class 4 on admission, time to onset, anterior myocardial infarction, systolic blood pressure, left ventricular ejection fraction, estimated GFR of $<60 \mathrm{ml} \cdot \mathrm{min}^{-1} \cdot 1.73 \mathrm{~m}^{-2}$, quartiles of glucose, multivessel disease, contrast volume, duration of procedure, and procedure success. The odds ratio (OR) and 95\% confidence intervals (CI) were presented in the final multivariate model. A 2-sided P-value of $<0.05$ was considered significant.

\section{Results}

\section{Incidence of Cl-AKI and Clinical Characteristics}

The patient flow diagram and selection process for inclusion in the study is shown in Figure 1. Of 845 consecutive patients with ACS who underwent emergency PCI, 115 patients were excluded (use of contrast volume more than MACD in 98 patients, emergency coronary bypass surgery in 3 patients, and chronic dialysis in 14). Thus, 730 consecutive patients (584 men and 146 women, median age of 64 years) were enrolled in this study. The GRACE Risk Score was 136 (112-156) in all patients, 147 (131-165) in patients with ST-segment elevation myocardial infarction, and 112 (89-122) those with unstable angina and non-ST-segment elevation myocardial infarction. Of the 730 patients, 212 (29\%) patients developed CI-AKI. Baseline clinical and angiographic characteristics according to the presence of CI-AKI are shown in Table 1.

Patients with CI-AKI were older, and had a higher prevalence of diabetes, ST-segment elevation myocardial infarction, Killip class 4 on admission, estimated GFR of $<60 \mathrm{ml} \cdot \mathrm{min}^{-1}$. $1.73 \mathrm{~m}^{-2}$, or multivessel disease, and higher glucose levels compared with those without CI-AKI. Patients with CI-AKI had a lower left ventricular ejection fraction. However, the location of the culprit lesion, the contrast volume, procedure duration, and procedure success rate did not significantly differ between patients who developed CI-AKI and those who did not. Treatment with sulfonylurea, $\alpha$-glucosidase inhibitor, and thiazolidinediones was more frequent in patients who developed CIAKI. Treatment with angiotensin-converting enzyme inhibitors and/or angiotensin receptor blockers, $\beta$-blockers, calcium-channel blockers, statins, metformin, insulin, and atrial natriuretic peptide infusion was similar in these 2 groups. The prevalence of use and total dose of aspirin, either ticlopidine or clopidogrel, warfarin, and a fibriolytic agent before and after emergency PCI were similar in these 2 groups.

\section{CI-AKI and In-Hospital Outcome}

Patients with CI-AKI experienced a more complicated in-hospital clinical course (Table 2). The overall in-hospital mortality rate in the entire population was $3.7 \%$ (27 patients). The causes for in-hospital deaths were cardiogenic shock in 6 , refractory heart failure in 11, multi-organ failure in 4, sudden death in 3, ischemic stroke in 2, and left ventricular free-wall rupture in 1. Patients who developed CI-AKI had a higher risk for in-hospital mortality compared with those who did not (9.4\% vs. $1.5 \% ; \mathrm{P}<0.001)$.

Furthermore, the length of coronary care unit stay of patients with CI-AKI was longer than those without CI-AKI (3.0 
Table 3. Univariate and Multivariate Predictors of $\mathrm{Cl}-\mathrm{AKI}$ in Entire Patients

\begin{tabular}{|c|c|c|c|c|c|c|}
\hline & \multicolumn{3}{|c|}{ Univariate analysis } & \multicolumn{3}{|c|}{ Multivariate analysis } \\
\hline & OR & $95 \% \mathrm{Cl}$ & $P$ value & OR & $95 \% \mathrm{Cl}$ & $P$ value \\
\hline Age (per 10 years increment) & 1.26 & $1.07-1.49$ & 0.005 & 1.17 & $0.96-1.42$ & 0.12 \\
\hline Male & 1.03 & $0.69-1.54$ & 0.89 & 1.50 & $0.93-2.45$ & 0.10 \\
\hline Hypertension & 1.08 & $0.78-1.49$ & 0.64 & 1.06 & $0.74-1.53$ & 0.75 \\
\hline Hyperlipidemia & 0.90 & $0.64-1.27$ & 0.54 & 1.08 & $0.73-1.60$ & 0.69 \\
\hline Diabetes mellitus & 2.21 & $1.56-3.12$ & $<0.001$ & 1.14 & $0.74-1.75$ & 0.56 \\
\hline Current smoker & 0.89 & $0.64-1.23$ & 0.47 & 1.20 & $0.81-1.78$ & 0.37 \\
\hline Previous MI & 0.97 & $0.59-1.61$ & 0.92 & 0.69 & $0.38-1.24$ & 0.21 \\
\hline ST-segment elevation MI & 1.60 & $1.11-2.29$ & 0.01 & 1.00 & $0.65-1.54$ & 0.99 \\
\hline Killip class 4 on admission & 2.33 & $1.05-5.20$ & 0.04 & 1.37 & $0.53-3.59$ & 0.52 \\
\hline Time to onset $(\mathrm{h})$ & 0.99 & $0.98-1.00$ & 0.08 & 1.00 & $0.98-1.01$ & 0.59 \\
\hline Anterior MI & 1.06 & $0.77-1.46$ & 0.71 & 1.09 & $0.75-1.58$ & 0.66 \\
\hline SBP $(\mathrm{mmHg})$ (per $10 \mathrm{mmHg}$ increment) & 1.00 & $0.94-1.07$ & 0.93 & 1.05 & $0.98-1.13$ & 0.17 \\
\hline LVEF (per $10 \%$ increment) & 0.71 & $0.60-0.84$ & $<0.001$ & 0.80 & $0.65-0.98$ & 0.03 \\
\hline Estimated GFR $\left(<60 \mathrm{ml} \cdot \mathrm{min}^{-1} \cdot 1.73 \mathrm{~m}^{-2}\right)$ & 2.10 & $1.36-3.24$ & $<0.001$ & 2.32 & $1.35-3.99$ & 0.002 \\
\hline [Estimated GFR (per $10 \mathrm{ml} \cdot \mathrm{min}^{-1} \cdot 1.73 \mathrm{~m}^{-2}$ increment)] & $(1.01)$ & $(0.96-1.06)$ & $(0.66)$ & - & - & - \\
\hline \multicolumn{7}{|l|}{ Glucose as variables categorized into quartiles (mg/dl) } \\
\hline 1 st quartile $(<120)$ & 1.0 & & & 1.0 & & \\
\hline 2nd quartile (120-152) & 2.32 & $1.19-4.51$ & 0.01 & 2.91 & $1.48-5.70$ & 0.002 \\
\hline 3rd quartile (153-207) & 6.56 & $3.52-12.2$ & $<0.001$ & 7.32 & $3.79-14.2$ & $<0.001$ \\
\hline 4th quartile (>207) & 12.7 & $6.85-23.6$ & $<0.001$ & 12.0 & $6.03-23.9$ & $<0.001$ \\
\hline Multivessel disease & 1.63 & $1.18-2.24$ & 0.003 & 1.34 & $0.92-1.94$ & 0.12 \\
\hline Contrast volume (per $10 \mathrm{ml}$ increment) & 0.99 & $0.98-1.02$ & 0.83 & 1.00 & $0.97-1.03$ & 0.93 \\
\hline Duration of procedure (per $10 \mathrm{~min}$ increment) & 1.00 & $0.99-1.01$ & 0.46 & 0.95 & $0.89-1.01$ & 0.13 \\
\hline Procedural failures & 0.64 & $0.23-1.74$ & 0.68 & 0.94 & $0.30-2.93$ & 0.92 \\
\hline Intra-aortic balloon pumping support & 1.52 & $0.99-2.34$ & 0.06 & 0.89 & $0.53-1.52$ & 0.68 \\
\hline
\end{tabular}

OR, odds ratio; $\mathrm{Cl}$, confidence interval. Other abbreviations as in Table 1.

[3.0-4.0] vs. $4.0[3.0-6.0]$ days; $\mathrm{P}<0.001)$.

\section{Independent Predictors of CI-AKI}

In the multivariate logistic analysis including 20 clinical and biochemical variables, quartiles of glucose levels (1st quartile, $<120 \mathrm{mg} / \mathrm{dl}$; 2nd quartile, $120-152 \mathrm{mg} / \mathrm{dl}$; 3rd quartile, $153-$ $207 \mathrm{mg} / \mathrm{dl}$; and 4 th quartile $>207 \mathrm{mg} / \mathrm{dl}$ ), estimated GFR of $<60 \mathrm{ml} \cdot \mathrm{min}^{-1} \cdot 1.73 \mathrm{~m}^{-2}$, and left ventricular ejection fraction were independently associated with the development of CIAKI (Table 3). In addition, in both sub-analysis of patients with known diabetes (1st quartile, $<150 \mathrm{mg} / \mathrm{dl}$; 2 nd quartile, $150-219 \mathrm{mg} / \mathrm{dl}$; 3rd quartile, $220-285 \mathrm{mg} / \mathrm{dl}$; and 4th quartile, $>285 \mathrm{mg} / \mathrm{dl}$ ) and that of those without known diabetes (1st quartile $<117 \mathrm{mg} / \mathrm{dl}$; 2nd quartile, $117-140 \mathrm{mg} / \mathrm{dl}$; 3rd quartile, $141-180 \mathrm{mg} / \mathrm{dl}$; and 4 th quartile, $>180 \mathrm{mg} / \mathrm{dl}$ ), quartiles of glucose levels remained significant independent predictors of CIAKI (Table 4).

\section{Incidence of CI-AKI and Quartiles of Glucose Levels}

The incidence of CI-AKI according to quartiles of glucose levels in all patients, patients with and without known diabetes is shown in Figure 2. Considering the entire population, the rate of CI-AKI gradually elevated with increasing quartiles of glucose levels $(8.1 \%, 17.0 \%, 37.4 \%$, and $52.5 \%$ in the 1 st, 2 nd, 3rd, and 4th quartiles, respectively). In patients with known diabetes, patients with $2 \mathrm{nd}, 3 \mathrm{rd}$, and 4 th quartiles had a higher risk for CI-AKI compared to those with the lowest quartile. Similarly, patients of 3rd and 4th quartiles had a higher risk for CI-AKI compared with those with the 1 st and 2 nd quartiles in the non-diabetic group.

\section{Discussion}

We have demonstrated that $\mathrm{CI}-\mathrm{AKI}$ is a frequent complication after emergency PCI in patients with ACS, even when the contrast volume did not exceed MACD. We also showed that CI-AKI might be significantly associated with a complicated clinical course, and that the pre-procedural glucose level could be a powerful and independent risk factor for the development of CI-AKI in this population. These findings suggest that additional pharmacologic or non-pharmocologic strategies might be needed to decrease the risk of CI-AKI, especially for patients with high glucose levels, even when the contrast volume does not exceed MACD.

In the present study, the pre-procedural glucose level was a strong and independent risk factor for the development of CI-AKI in both diabetic and non-diabetic patients with ACS. These findings have important clinical implications, primarily in identifying the high-risk patients who might benefit from pre-procedural CI-AKI prophylaxis and also by highlighting a potential target for intervention in the prevention of CI-AKI. Furthermore, the question might be raised of whether interventions such as intensive insulin therapy might reduce the risk of CI-AKI in patients with acute hyperglycemia. This issue should be evaluated in a future trial.

Adequate volume expansion is a well-established strategy in the prevention of CI-AKI. ${ }^{21-23}$ Although full pre-procedural volume expansion was not possible because of emergency situations, saline hydration performed soon after PCI and prolonged for $12 \mathrm{~h}$ in the present study had no major effect on the prevention of CI-AKI. CI-AKI still occurred frequently (at a 


\begin{tabular}{|c|c|c|c|c|c|c|}
\hline \multirow{2}{*}{ Multivariate model of contrast-induced AKI } & \multicolumn{3}{|c|}{ Diabetic patients $(n=197)$} & \multicolumn{3}{|c|}{ Non-diabetic patients $(n=533)$} \\
\hline & OR & $95 \% \mathrm{Cl}$ & $P$ value & OR & $95 \% \mathrm{Cl}$ & P value \\
\hline Age (per 10 years increment) & 1.59 & $1.02-2.47$ & 0.04 & 1.06 & $0.84-1.33$ & 0.62 \\
\hline Male & 2.79 & $1.12-6.92$ & 0.03 & 1.37 & $0.75-2.49$ & 0.31 \\
\hline Hypertension & 0.97 & $0.48-1.96$ & 0.94 & 1.02 & $0.65-1.59$ & 0.94 \\
\hline Hyperlipidemia & 1.11 & $0.54-2.28$ & 0.78 & 1.06 & $0.65-1.72$ & 0.82 \\
\hline Current smoker & 1.53 & $0.71-3.29$ & 0.27 & 1.04 & $0.64-1.67$ & 0.88 \\
\hline Previous MI & 0.53 & $0.18-1.58$ & 0.25 & 0.66 & $0.31-1.42$ & 0.29 \\
\hline ST-segment elevation MI & 1.06 & $0.48-2.36$ & 0.88 & 0.99 & $0.58-1.69$ & 0.97 \\
\hline Killip class 4 on admission & 1.02 & $0.16-6.49$ & 0.99 & 1.74 & $0.55-5.50$ & 0.35 \\
\hline Time to onset (per 1 increment) & 0.99 & $0.97-1.02$ & 0.51 & 1.00 & $0.98-1.02$ & 0.80 \\
\hline Anterior MI & 0.97 & $0.47-1.97$ & 0.93 & 1.17 & $0.74-1.84$ & 0.50 \\
\hline SBP (per $10 \mathrm{mmHg}$ increment) & 1.04 & $0.89-1.21$ & 0.64 & 1.07 & $0.99-1.17$ & 0.11 \\
\hline LVEF (per $10 \%$ increment) & 0.65 & $0.44-0.96$ & 0.03 & 0.88 & $0.68-1.12$ & 0.30 \\
\hline Estimated GFR $\left(<60 \mathrm{ml} \cdot \mathrm{min}^{-1} \cdot 1.73 \mathrm{~m}^{-2}\right)$ & 2.05 & $0.78-5.39$ & 0.14 & 2.85 & $1.41-5.75$ & 0.004 \\
\hline \multicolumn{7}{|l|}{$\begin{array}{l}\text { Glucose as variables categorized into quartiles (mg/dl) } \\
\text { [Diabetic/Non-diabetic] }\end{array}$} \\
\hline 1 st quartile $[(<150) /(<117)]$ & 1.0 & & & 1.0 & & \\
\hline 2nd quartile $[(150-219) /(117-140)]$ & 6.03 & $1.96-18.6$ & 0.002 & 2.03 & $0.87-4.71$ & 0.10 \\
\hline 3rd quartile $[(220-285) /(141-180)]$ & 8.20 & $2.67-25.2$ & $<0.001$ & 4.88 & $2.19-10.9$ & $<0.001$ \\
\hline 4th quartile $[(>285) /(>180)]$ & 10.9 & $3.40-34.9$ & $<0.001$ & 10.6 & $4.76-23.8$ & $<0.001$ \\
\hline Multivessel disease & 1.12 & $0.56-2.25$ & 0.75 & 1.45 & $0.92-2.30$ & 0.11 \\
\hline Contrast volume (per $10 \mathrm{ml}$ increment) & 0.96 & $0.90-1.02$ & 0.21 & 1.02 & $0.98-1.06$ & 0.28 \\
\hline Duration of procedure (per $10 \mathrm{~min}$ increment) & 0.98 & $0.88-1.09$ & 0.74 & 0.94 & $0.86-1.02$ & 0.12 \\
\hline Procedural failures & 3.52 & $0.45-27.5$ & 0.23 & 0.39 & $0.07-2.31$ & 0.30 \\
\hline Intra-aortic balloon pumping support & 0.64 & $0.24-1.70$ & 0.37 & 1.16 & $0.60-2.22$ & 0.66 \\
\hline
\end{tabular}

Abbreviations as in Tables 1,3.

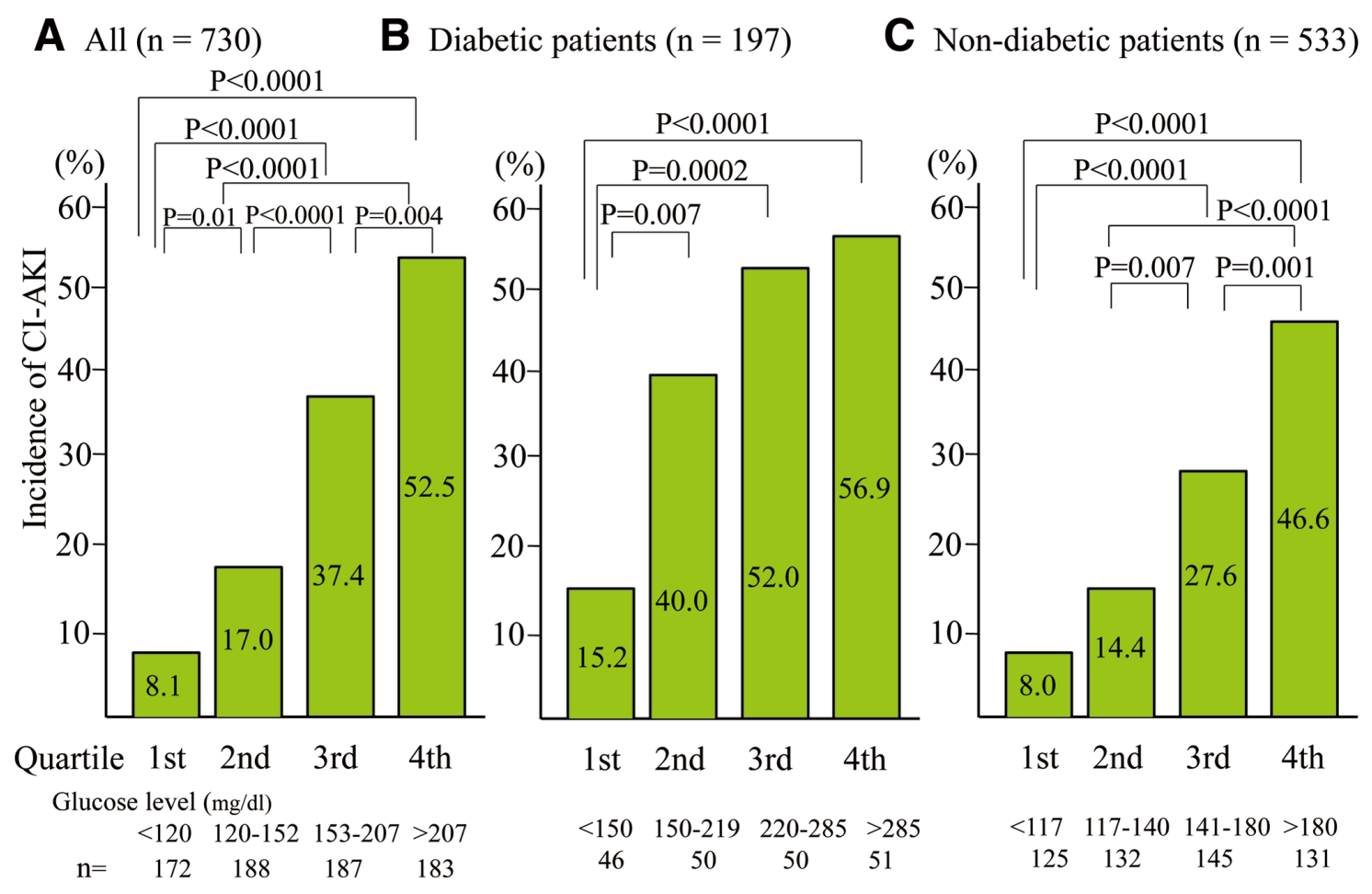

Figure 2. Incidences of contrast-induced acute kidney injury (CI-AKI) according to quartiles of glucose level in entire population (A), diabetic (B), and non-diabetic patients (C). 
rate of about $30 \%$ ), particularly in patients with acute hyperglycemia. Thus, additional preventative strategies aimed at protecting the kidney are required, especially in patients with acute hyperglycemia even when the contrast volume does not exceed MACD.

Contrast volume is a key risk factor for CI-AKI. In the present study, CI-AKI occurred commonly in patients with ACS undergoing PCI even when contrast volume did not exceed $\mathrm{MACD}$, and no relationship could be found between the amount of contrast used and the development of CI-AKI. Thus, other factors, such as acute hyperglycemia, impaired renal function, and low left ventricular ejection fraction might contribute more to the development of CI-AKI than contrast volume in this population. Additionally, no universal definition of CI-AKI exists. Based on the definition of CI-AKI used in the present study, all patients with an increase in creatinine of $>25 \%$ were considered to have CI-AKI. This means that a patient with a creatinine value from $0.8 \mathrm{mg} / \mathrm{dl}$ to $1.01 \mathrm{mg} / \mathrm{dl}$ would be considered to have CI-AKI. This definition might be much too broad, and it could be extremely difficult to attribute such mild/moderate increases to contrast volume rather than to a number of other possible explanations. These findings suggest that a broader term such as deterioration in renal function would be much more appropriate than the term CI-AKI used in the present study.

Our study found that left ventricular ejection fraction and estimated GFR of $<60 \mathrm{ml} \cdot \mathrm{min}^{-1} \cdot 1.73 \mathrm{~m}^{-2}$ were also independently associated with the risk of CI-AKI. The statistical power for this finding was weaker compared with the factor of preprocedural glucose levels. Thus, acute hyperglycemia might play a critical role in the pathogenesis of the development of CI-AKI in this population. The mechanism underlying the association between acute hyperglycemia and the risk of CIAKI has not been yet elucidated. An experimental study has suggested that hyperglycemia per se exacerbates renal injury through mitochondrial dysfunction. ${ }^{24}$ Elevated glucose levels also have been shown to be associated with endothelial dysfunction, ${ }^{25}$ increased activation of prothrombotic factors, 26,27 markers of vascular inflammation, ${ }^{28,29}$ and generation of reactive oxygen species, ${ }^{30,31}$ suggesting that there are also contributing factors to the development of CI-AKI.

Whether hyperglycemia is a marker of increased comorbidity burden and disease severity or a direct mediator of CI-AKI remains uncertain. The mechanism underlying the development of hyperglycemia in ACS patients also has not yet been elucidated. Acute hyperglycemia is usually regarded as a reaction to stress or postprandial hyperglycemia as a result of poor glucose control. Thus, hyperglycemia could reflect disease severity resulting from a high catecholamine state and increased circulating concentrations of cortisol, especially in non-diabetic patients, suggesting that hyperglycemia might be a marker of increased comorbidity burden and disease severity. However, multivariate analyses including major clinical variables associated with hemodynamics and disease severity, such as Killip class, anterior myocardial infarction, left ventricular ejection fraction, multivessel disease, and intra-aortic balloon pumping support, demonstrated that hyperglycemia was the strongest and an independent predictor of CI-AKI regardless of the presence of known diabetes. These multivariate results and previous experimental studies ${ }^{24-31}$ suggest that hyperglycemia might be a direct mediator of CI-AKI findings, and should be investigated in future studies.

Recently, Stolker and co-workers 1st demonstrated that the pre-procedural glucose level might be a risk factor for CI-AKI in non-diabetic patients undergoing coronary angiography for
AMI $;{ }^{17}$ however, this was not observed in diabetic patients, who experienced high rates of CI-AKI regardless of pre-procedural glucose levels. More recently, Marenzi and co-workers also showed similar results in patients undergoing primary PCI for ST-segment elevation myocardial infarction. ${ }^{18}$ However, we observed that the pre-procedural glucose level was closely associated with a risk for CI-AKI in both diabetic and non-diabetic patients. The causes for the discordant result in diabetic patients are unclear. Marenzi and co-workers have shown no relationship between pre-procedural glucose levels and the risk of CI-AKI in non-diabetic patients with severe renal dysfunction (estimated GFR of $<30 \mathrm{ml} \cdot \mathrm{min}^{-1} \cdot 1.73 \mathrm{~m}^{-2}$ ), perhaps because of the higher baseline risk for CI-AKI. As we excluded patients whose contrast volume exceeded MACD, our diabetic patients had a lower frequency of severe renal dysfunction compared with patients in previous studies. The lower severity of renal dysfunction might contribute to the close association between elevated pre-procedural glucose levels and the risk of CI-AKI in diabetic patients. In addition, patients in previous studies more frequently received insulin in comparison with our patients. ${ }^{17}$ The differences in the severity of diabetes observed in our study and in previous studies might explain this discrepant result in the diabetic patients. Finally, several demographic studies have assessed ethnic differences in insulin sensitivity and $\beta$-cell function between Asian and white diabetic patients. ${ }^{32,33}$ The ethnic differences might cause discrepant results in diabetic patients.

\section{Study Limitations}

Our study has several limitations. First, the present study was a single-center study; our findings should be confirmed in a large multicenter trial. This study highlighted the incidence, risk factors, and outcome of CI-AKI only in patients with ACS undergoing PCI whose contrast volume was below MACD. Future investigations are required to explore the application of our findings to all patients with ACS, patients with ACS undergoing coronary angiography, and patients with ACS not undergoing angiography/PCI. Also, our findings could be applied to patients with stable coronary artery disease undergoing coronary angiography/PCI. This issue should be evaluated in future studies.

Second, an oral glucose tolerance test was not routinely conducted before discharge in this study. Patients were designed as having diabetes in this study if they had a previous diagnosis of diabetes or received anti-diabetic treatment, but some diabetic patients might not have been diagnosed as having diabetes. However, the proportion of our participants who had diabetes was consistent with that of previous studies. ${ }^{11,34-36}$ Quartiles of glucose levels were independently associated with development of CI-AKI in both diabetic and non-diabetic patients. Furthermore, Ishihara et al. reported that admission hyperglycemia in non-diabetic patients with AMI dose not represent previously undiagnosed diabetes. ${ }^{37} \mathrm{We}$ therefore believe that this factor did not contribute substantially to our results.

Finally, we did not investigate whether aggressive management of glucose levels in hyperglycemic patients can decrease the incidence of CI-AKI. These issues should be evaluated in a future trial.

\section{Conclusions}

CI-AKI might occur commonly and could be associated with a more complicated clinical course in patients with ACS undergoing emergency PCI patients, even when contrast volume does not exceed MACD. An elevated pre-procedural glucose 
level could be a powerful and independent risk factor for the development of CI-AKI regardless of the presence of known diabetes in this population.

\section{Acknowledgments}

We are grateful to all the staff of the catheterization laboratory, coronary care unit, and cardiac wards at Fujita Health University Hospital for their dedication and contribution.

\section{Disclosures}

None.

\section{References}

1. Bagshaw SM, Ghali WA. Acetylcysteine for prevention of contrastinduced nephropathy after intravascular angiography: A systematic review and meta-analysis. BMC Med 2004; 2: 38.

2. Tumlin J, Stacul F, Adam A, Becker CR, Davidson C, Lameire N, et al. Pathophysiology of contrast-induced nephropathy. Am J Cardiol 2006; 98: $14 \mathrm{~K}-20 \mathrm{~K}$.

3. Brown JR, Robb JF, Block CA, Schoolwerth AC, Kaplan AV, O'Connor GT, et al. Does safe dosing of iodinated contrast prevent contrast-induced acute kidney injury? Circ Cardiovasc Interv 2010; 3: $346-350$.

4. McCullough PA, Wolyn R, Rocher L, Levin RN, O'Neill WW. Acute renal failure after coronary intervention: Incidence, risk factors, and relationship to mortality. Am J Med 1997; 103: 368-375.

5. Marenzi G, Lauri G, Assanelli E, Campodonico J, Metrio MD, Marana I, et al. Contrast-induced nephropathy in patients undergoing primary angioplasty for acute myocardial infarction. $J \mathrm{Am}$ Coll Cardiol 2004; 44: 1780-1785.

6. Senoo T, Motohiro M, Kamihata H, Yamamoto S, Isono T, Manabe $\mathrm{K}$, et al. Contrast-induced nephropathy in patients undergoing emergency percutaneous coronary intervention for acute coronary syndrome. Am J Cardiol 2010; 105: 624-628.

7. Cigarroa RG, Lange L, Williams RH, Hillis D. Dosing of contrast material to prevent contrast nephropathy in patients with renal disease. Am J Med 1989; 86: 649-652.

8. Freeman RV, O'Donnell M, Share D, Meenge WL, Kline-Rogers E, Clark VL, et al. Nephropathy requiring dialysis after percutaneous coronary intervention and the critical role of an adjusted contrast dose. Am J Cardiol 2002; 90: 1068-1073.

9. Marenzi G, Assanelli E, Campodonico J, Lauri G, Marana I, Metrio $\mathrm{M}$, et al. Contrast volume during primary percutaneous coronary intervention and subsequent contrast-induced nephropathy and mortality. Ann Intern Med 2009; 150: 170-177.

10. Deedwania P, Kosiborod CM, Barret E, Ceriello A, Isley W, Mazzone $\mathrm{T}$, et al. Hyperglycemia and acute coronary syndrome: A scientific statement from the American Heart Association Diabetes Committee of the Council on Nutrition, Physical Activity, and Metabolism. Circulation 2008; 117: 1610-1619.

11. Kosiborod M, Rathore SS, Inzucchi SE, Masoudi FA, Wang Y, Havranek EP, et al. Admission glucose and mortality in elderly patients hospitalized with acute myocardial infarction: Implications for patients with and without recognized diabetes. Circulation 2005; 111: $3078-3086$.

12. Bellodi G, Manicardi V, Malavasi V, Veneri L, Bernini G, Bossini P, et al. Hyperglycemia and prognosis of acute myocardial infarction in patients without diabetes mellitus. Am J Cardiol 1989; 64: 885-888.

13. Capes SE, Hunt D, Malmberg K, Gerstein HC. Stress hyperglycaemia and increased risk of death after myocardial infarction in patients with and without diabetes: A systematic overview. Lancet 2000; 355: 773-778.

14. Goyal A, Mahaffey KW, Garg J, Nicolau JC, Hochman JS, Weaver $\mathrm{WD}$, et al. Prognostic significance of the change in glucose level in the first $24 \mathrm{~h}$ after acute myocardial infarction: Results from the CARDINAL study. Eur Heart J 2006; 27: 1289-1297.

15. Svensson AM, McGuire DK, Abrahamsson P, Dellborg M. Association between hyper- and hypoglycaemia and 2 year all-cause mortality risk in diabetic patients with acute coronary events. Eur Heart $J$ 2005; 26: 1255-1261.

16. Kadri Z, Danchin N, Vaur L, Cottin Y, Gueret P, Zeller M, et al. Major impact of admission glycaemia on 30 day and one year mortality in non-diabetic patients admitted for myocardial infarction: Results from the nationwide French USIC 2000 study. Heart 2006; 92: 910-915.
17. Stolker JM, MuCullough PA, Rao S, Inzucchi SE, Spertus JA, Maddox TM, et al. Pre-procedural glucose levels and the risk for contrastinduced acute kidney injury in patients undergoing coronary angiography. J Am Coll Cardiol 2010; 55: 1433-1440.

18. Marenzi G, Metrio MD, Rubino M, Lauri G, Cavallero A, Assanelli $\mathrm{E}$, et al. Acute hyperglycemia and contrast-induced nephropathy in primary percutaneous coronary intervention. Am Heart J 2010; 160: $1170-1177$.

19. Granger CB, Goldberg RJ, Dabbous O, Pieper KS, Eagle KA, Cannon $\mathrm{CP}$, et al. Prediction of hospital mortality in the global registry of acute coronary events. Arch Intern Med 2003; 163: 2345-2353.

20. Matsuo S, Imai E, Horio M, Yasuda Y, Tomita K, Nitta K, et al. Revised equations for estimated GFR from serum creatinine in Japan. Am J Kidney Dis 2009; 53: 982-992.

21. Mueller C, Buerkle G, Buettner H, Petersen J, Perruchoud AP, Eriksson U, et al. Prevention of contrast media-associated nephropathy: Randomized comparison of 2 hydration regimens in 1620 patients undergoing coronary angioplasty. Arch Intern Med 2002; 162: 329-336.

22. Stacul F, Adam A, Becker CR, Davidson C, Lameire N, McCullough PA, et al. Strategies to reduce the risk of contrast-induced nephropathy. Am J Cardiol 2006; 98: 59K-77K.

23. Trivedi HS, Moore H, Nasr S, Aggarwal K, Agrawal A, Goel P, et al. A randomized prospective trial to assess the role of saline hydration on the development of contrast nephrotoxicity. Nephron Clin Pract 2003; 93: C29-C34.

24. Vanhorebeek I, Gunst J, Ellger B, Boussemaere M, Lerut E, Debaveye $\mathrm{Y}$, et al. Hyperglycemic kidney damage in an animal model of prolonged critical illness. Kidney Int 2009; 76: 512-520.

25. Kawano H, Motoyama T, Hirashima O, Hirai N, Miyao Y, Sakamoto $\mathrm{T}$, et al. Hyperglycemia rapidly suppresses flow-mediated endothelium-dependent vasodilation of brachial artery. J Am Coll Cardiol 1999; 34: 146-154.

26. Pandolfi A, Giaccari A, Cilli C, Alberta MM, Morviducci L, De Filippis EA, et al. Acute hyperglycemia and acute hyperinsulinemia decrease plasma fibrinolytic activity and increase plasminogen activator inhibitor type 1 in the rat. Acta Diabetol 2001; 38: 71-76.

27. Gresele P, Guglielmini G, DeAngelis M, Ciferri S, Ciofetta M, Falcinelli E, et al. Acute, short-term hyperglycemia enhances shear stress-induced platelet activation in patients with type II diabetes mellitus. $J$ Am Coll Cardiol 2003; 41: 1013-1020.

28. Morohoshi M, Fujisawa K, Uchimura I, Numano F. Glucose-dependent interleukin 6 and tumor necrosis factor production by human peripheral blood monocytes in vitro. Diabetes 1996; 45: 954-959.

29. Esposito K, Nappo F, Marfella R, Giugliano G, Giugliano F, Ciotola $\mathrm{M}$, et al. Inflammatory cytokine concentrations are acutely increased by hyperglycemia in humans: Role of oxidative stress. Circulation 2002; 106: 2067-2072.

30. Guha M, Bai W, Nadler JL, Natarajan R. Molecular mechanisms of tumor necrosis factor alpha gene expression in monocytic cells via hyperglycemia-induced oxidant stress-dependent and -independent pathways. J Biol Chem 2000; 275: 17728-17739.

31. Mohanty P, Hamouda W, Garg R, Aljada A, Ghanim H, Dandona P. Glucose challenge stimulates reactive oxygen species (ROS) generation by leucocytes. J Clin Endocrinol Metab 2000; 85: 2970-2973.

32. Torrens JI, Skurnick J, Davidow AL, Korenman SG, Santoro N, Soto-Greene M, et al. Ethnic differences in insulin sensitivity and beta-cell function in premenopausal or early perimenopausal women without diabetes: The Study of Women's Health Across the Nation (SWAN). Diabetes Care 2004; 27: 354-361.

33. Shai I, Jiang R, Manson JE, Stampfer MJ, Willett WC, Colditz GA, et al. Ethnicity, obesity, and risk of type 2 diabetes in women: A 20year follow-up study. Diabetes Care 2006; 29: 1585-1590.

34. Menon V, Lessard D, Yarzebski J, Furman MI, Gore JM, Goldberg RJ. Leukocytosis and adverse hospital outcomes after acute myocardial infarction. Am J Cardiol 2003; 92: 368-372.

35. Hiro T, Kimura T, Morimoto T, Miyauchi K, Nakagawa Y, Yamagishi $\mathrm{M}$, et al. Diabetes mellitus is a major negative determinant of coronary plaque regression during statin therapy in patients with acute coronary syndrome. Circ J 2010; 74: 1165-1174.

36. Kume N, Mitsuoka H, Hayashida K, Tanaka M, Kita T. Soluble lectin-like oxidized low-density lipoprotein receptor-1 predicts prognosis after acute coronary syndrome. Circ J 2010; 74: 1399-1404.

37. Ishihara M, Inoue I, Kawagoe T, Shimatani Y, Kurisu S, Hata T, et al. Is admission hyperglycemia in non-diabetic patients with acute myocardial infarction a surrogate for previously undiagnosed abnormal glucose tolerance? Eur Heart J 2006; 27: 2413-2419. 